University of Montana

ScholarWorks at University of Montana

$5-2010$

\title{
Testing Hypotheses for Exotic Plant Success: Parallel Experiments in the Native and Introduced Ranges
}

Jennifer L. Williams

Harald Auge

John L. Maron

University of Montana - Missoula, john.maron@mso.umt.edu

Follow this and additional works at: https://scholarworks.umt.edu/biosci_pubs

Part of the Biology Commons

Let us know how access to this document benefits you.

\section{Recommended Citation}

Williams, Jennifer L.; Auge, Harald; and Maron, John L., "Testing Hypotheses for Exotic Plant Success:

Parallel Experiments in the Native and Introduced Ranges" (2010). Biological Sciences Faculty

Publications. 321.

https://scholarworks.umt.edu/biosci_pubs/321

This Article is brought to you for free and open access by the Biological Sciences at ScholarWorks at University of Montana. It has been accepted for inclusion in Biological Sciences Faculty Publications by an authorized administrator of ScholarWorks at University of Montana. For more information, please contact

scholarworks@mso.umt.edu. 


\title{
Testing hypotheses for exotic plant success: parallel experiments in the native and introduced ranges
}

\author{
Jennifer L. Williams, ${ }^{1,3}$ Harald Auge, ${ }^{2}$ and John L. Maron ${ }^{1}$ \\ ${ }^{1}$ Division of Biological Sciences, University of Montana, Missoula, Montana 59812 USA \\ ${ }^{2}$ Department of Community Ecology, UFZ, Helmholtz Center for Environmental Research, D-06120 Halle, Germany
}

\begin{abstract}
A central question in ecology concerns how some exotic plants that occur at low densities in their native range are able to attain much higher densities where they are introduced. This question has remained unresolved in part due to a lack of experiments that assess factors that affect the population growth or abundance of plants in both ranges. We tested two hypotheses for exotic plant success: escape from specialist insect herbivores and a greater response to disturbance in the introduced range. Within three introduced populations in Montana, USA, and three native populations in Germany, we experimentally manipulated insect herbivore pressure and created small-scale disturbances to determine how these factors affect the performance of houndstongue (Cynoglossum officinale), a widespread exotic in western North America. Herbivores reduced plant size and fecundity in the native range but had little effect on plant performance in the introduced range. Small-scale experimental disturbances enhanced seedling recruitment in both ranges, but subsequent seedling survival was more positively affected by disturbance in the introduced range. We combined these experimental results with demographic data from each population to parameterize integral projection population models to assess how enemy escape and disturbance might differentially influence $C$. officinale in each range. Model results suggest that escape from specialist insects would lead to only slight increases in the growth rate $(\lambda)$ of introduced populations. In contrast, the larger response to disturbance in the introduced vs. native range had much greater positive effects on $\lambda$. These results together suggest that, at least in the regions where the experiments were performed, the differences in response to small disturbances by $C$. officinale contribute more to higher abundance in the introduced range compared to at home. Despite the challenges of conducting experiments on a wide biogeographic scale and the logistical constraints of adequately sampling populations within a range, this approach is a critical step forward to understanding the success of exotic plants.
\end{abstract}

Key words: Cynoglossum officinale; disturbance; escape from enemies; herbivory; integral projection model (IPM); Life Table Response Experiment (LTRE); Montana, USA; native and introduced ranges; plant demography; Saxony-Anhalt, Germany.

\section{INTRODUCTION}

Among the ever-increasing number of introduced species are a subset that now occur at dramatically greater abundance where introduced compared to where they are native. How some exotic species can attain these strikingly higher densities in their introduced ranges remains an unresolved problem in ecology. Although many hypotheses have been proposed to explain this pattern (Hierro et al. 2005), for plants, few have received rigorous experimental tests (Shea and Chesson 2002).

One of the oldest and most cited hypotheses for exotic plant success is the enemy escape hypothesis, which posits that release from specialist herbivores or pathogens drives the increase in abundance of an exotic

Manuscript received 18 November 2008; revised 25 June 2009; accepted 4 August 2009; final version received 1 September 2009. Corresponding Editor: W. P. Carson.

${ }^{3}$ Present address: National Center for Ecological Analysis and Synthesis, 735 State Street, Suite 300, Santa Barbara, California 93101 USA. E-mail: jwilliams@nceas.ucsb.edu species in its new range (Elton 1958, Keane and Crawley 2002). Increasing evidence indicates that exotic plants have reduced herbivore or pathogen loads where they are introduced (Memmott et al. 2000, Wolfe 2002, Mitchell and Power 2003, Torchin et al. 2003, Vilà et al. 2005) and thus less damage compared to where they are native (Reinhart et al. 2003, DeWalt et al. 2004). Yet, whether this difference in damage explains the sometimes dramatic increases in plant abundance across ranges remains unclear (Maron and Vilà 2001). Two conditions must be met for the enemy escape hypothesis to explain the differential success of exotic plants: first, plant population abundance must be limited by enemies in the native range; second, lower rates of attack or damage in recipient communities must translate to higher population growth or abundance (Jongejans et al. 2006).

A second hypothesis for invader success is that increased disturbance may give invaders an advantage in the introduced range (Baker 1974, Hobbs 1989, Davis 
et al. 2000, Mack et al. 2000). Disturbances are thought to facilitate invasion by opening safe sites for colonization and increasing resource availability, which ruderal invaders may be able to exploit more quickly than most native plants (Hobbs and Huenneke 1992, Seabloom et al. 2003). Only a few studies have directly tested the extent to which disturbances contribute to the success of an exotic plant (Parker 2001, Kellogg and Bridgham 2004, Hierro et al. 2006, Britton-Simmons and Abbott 2008). However, in their native ranges, exotic plants also encounter disturbance. For disturbance to contribute to the success of exotic plants that occur in disturbed patches at home, disturbances must occur more frequently in recipient communities, or the abundance or population growth rate of the exotic species must respond more positively to disturbance in the introduced range. The latter response could occur if there is reduced competition from co-occurring species following disturbance in the introduced range compared to in the native range.

The predictions for when each of these hypotheses should be supported highlight two important issues in invasion biology. First, these hypotheses explicitly pertain to processes that differentially influence plant performance and population growth at home vs. abroad. Thus understanding the causes of exotic plant success requires a biogeographical perspective involving parallel experiments in both ranges (Hierro et al. 2005). Unfortunately, such an approach is rare; much of invasion biology research is still conducted in only one range (Hierro et al. 2005). Second, although hypotheses for exotic success refer to factors that differentially influence abundance or population growth between ranges, tests of these hypotheses often evaluate the impacts of particular factors on individual rather than population performance. This is problematic because individual performance measures, such as seedling survival or adult growth, may have little impact on abundance or population growth. One way to circumvent this problem is to combine experimental results and demographic data in population models to forecast the effects of particular processes on population growth. Although demographic studies of plants are common (Harper 1977, Franco and Silvertown 2004), they are infrequently integrated with experimental studies in order to better understand exotic plant success (but see Parker 2001, Burns 2008).

Here we report results from parallel manipulative experiments conducted in three populations in the native and introduced ranges to test the roles of natural enemy escape and small-scale disturbances in explaining the success of houndstongue (Cynoglossum officinale), a widely distributed exotic plant. In the same six populations in which experiments were conducted, we quantified the demography of $C$. officinale and then used these data to parameterize integral projection models. The population models enabled us to forecast how herbivory or disturbance might differentially influence $C$. officinale population growth in both ranges. We recognize that three study populations within each range cannot possibly encapsulate all the processes that might influence or limit populations across each range. However, our approach is an important first step. Parallel experiments in each range, even if limited in number, can provide greater insight into the factors that may contribute to exotic success than could be gained from experiments conducted in only one range. Moreover, we also performed largerscale surveys across portions of the native and introduced ranges to quantify the difference in population abundance of $C$. officinale at home and abroad. These combined approaches enabled us to determine the difference between ranges in: (1) $C$. officinale population abundance, (2) the intensity of insect herbivory and how herbivore pressure influences individual performance, (3) the frequency of small-scale disturbances and the effects of experimental disturbances on plant recruitment and subsequent performance, and (4) the cumulative influences of these interacting factors on projected population growth.

\section{METHODS \\ Study system}

Houndstongue, Cynoglossum officinale L. (Boraginaceae), is a self-compatible, facultatively monocarpic perennial (de Jong et al. 1990) that forms a rosette of basal leaves in its first year after germinating in the early spring, overwinters as a rosette and taproot, and then bolts and flowers in the late spring or summer of its second or later years, depending on plant size and environmental conditions (see Plate 1). Each flower produces fruits consisting of up to four large nutlets that are barbed and dispersed on mammal fur; all seeds germinate within $2 \mathrm{~m}$ of adult plants unless they are dispersed (Boorman and Fuller 1984). Although most native plants die after they flower, a tiny percentage of individuals may flower a second time in the subsequent year, after which they die (de Jong et al. 1990). In the introduced range, the proportion of plants within a population that flower more than once can range from 2 to $45 \%$ (Williams 2009).

C. officinale is native to Europe, where it grows in disturbed sites, open woodlands, meadows, and sand dunes (de Jong et al. 1990). It was first introduced to North America in the mid-19th century as a feed contaminant and is now present across the United States and southern Canada, where it is particularly common in forest clearcuts and rangelands (Upadhyaya et al. 1988). It is classified as a noxious weed in six western states, where it occurs at high density (Upadhyaya et al. 1988). In its native range, $C$. officinale is attacked by a specialist root-boring weevil, Mogulones cruciger (see Plate 1). This weevil preferentially attacks large rosettes and flowering plants, and can reduce seed set (Prins et al. 1992, Schwarzlaender 1997). Native plants are also consumed by a specialist stem-boring 
weevil and two leaf-feeding flea beetles, Longitarsus spp. (Schwarzlaender 2000; M. Schwarzlaender, personal communication).

We selected three study populations located in the center of each range (map of locations in Appendix A) that occurred in broadly representative habitats, and that minimized climatic differences so that differences between ranges would not be obscured by large differences in climate. Thus our study populations were not chosen randomly, but were selected such that gross habitat structure and climate would be similar at sites across continents. In the native range, populations were located within $100 \mathrm{~km}$ of Halle, Saxony-Anhalt, Germany. These populations were in the rain shadow of the Harz Mountains of central Germany and thus experienced a climate similar to that in the intermountain west of the United States (Appendix B). Two populations grew in midsuccessional grasslands, and one occurred in an open woodland patch of Robinia and Quercus trees with an understory dominated by an annual grass (see Appendix $\mathrm{C}$ for a list of common species at each site). In the native range, $C$. officinale is commonly associated with habitats of similar structure. In the introduced range, study populations were within $150 \mathrm{~km}$ of Missoula, Montana, USA. Two of the populations occurred in grassland, and the third was in a former clearcut; all three sites were dominated by perennial bunch grasses (Appendix C). The study sites in Montana experienced at least occasional grazing by cattle, and cattle were present during the majority of the growing season at one of the grassland sites. In the introduced range, C. officinale is commonly associated with both grazing and logging activity, and our sites are typical of the habitats that it invades. We will refer to these study sites as occurring in either the native or introduced range throughout the paper, although we acknowledge that with three sites in each range, our scope of inference to address the entire range is limited.

To quantify differences in abundance across ranges, we measured plant density at an additional 10 sites in the native range (across $700 \mathrm{~km}$ in Hungary and Germany) and seven sites in the introduced range (across $500 \mathrm{~km}$ in Montana; Appendix A). Sites were haphazardly selected by looking for populations in suitable habitat in each range and at locations suggested by local botanists. Although it is possible that we may have biased our samples away from very low-density populations because of the difficulty of detecting very small populations, this bias would be the same in both ranges. In two $1 \times 10 \mathrm{~m}$ transects, we counted the number of vegetative and flowering plants (i.e., adult plants). Since these surveys were conducted opportunistically throughout the growing season, we did not include seedlings in the analysis.

\section{Small-scale disturbances}

We documented the amount of disturbance at each of the three primary study sites in each range using three 1 $\times 50 \mathrm{~m}$ transects haphazardly distributed across each site, but separated by at least $10 \mathrm{~m}$. We recorded the size and location of each disturbance, defined as turned over soil, and then calculated the proportion of disturbed ground in each transect.

Since disturbance is known to affect the success of early life stages in the native range (de Jong and Klinkhamer 1988), we examined the relative impacts of small-scale disturbances on recruitment and subsequent seedling establishment in both ranges. In late summer 2004 , we established four $25 \times 25 \mathrm{~cm}$ plots in each of six experimental blocks at each of the three primary sites in Germany and Montana. Half of the plots were cleared by clipping all vegetation to the ground, removing it from the plot, and then turning over the top $5-8 \mathrm{~cm}$ of soil with a small rake and hoe to simulate natural disturbances. The same researchers created the disturbances in both ranges, and the artificial disturbances looked similar to natural disturbances. In the native range, these natural disturbances are caused by rabbits (Oryctolagus cuniculus), moles (Talpa europaea), and wild boar (Sus scrofa); in the introduced range, they are caused by ground squirrels (Spermophilus spp.), gophers (Thomomys spp.), and cattle. We added seeds collected from the same site to plots at the end of the summer, when plants typically disperse their seeds. We added 0 or 80 seeds to each plot in 2004; this density was chosen to reflect the natural density of seeds that would drop under a parent plant. We repeated these experiments in summer 2005 in eight new experimental blocks at each site. Plots within a block were separated by $1 \mathrm{~m}$, and blocks by $20-100 \mathrm{~m}$. We followed germination of seeds in disturbed and control plots beginning in early spring 2005 and monitored survival and recruitment of both cohorts through 2007. In the plots where no seeds were added, seedlings very rarely recruited, and we do not report these results in detail (on average, these plots contained less than one seedling; J. L. Williams, unpublished data).

Small-scale disturbances may change not only the biotic environment by eliminating competition, but may also affect abiotic conditions, which in turn could affect plant performance. To determine whether experimental disturbances increased nutrient availability, we buried mixed-bed ion-exchange resin capsules (Unibest, Bozeman, Montana, USA) at a depth of $5 \mathrm{~cm}$ in early spring 2005 to disturbed and undisturbed plots in each of the six blocks at each site, where no $C$. officinale seeds were added. At the end of the growing season in 2005 we excavated the resin capsules, and subsequently extracted $\mathrm{NO}_{3}{ }^{-}$and $\mathrm{NH}_{4}{ }^{+}$by bathing each capsule in three sequential 30 -minute rinses of $2 \mathrm{M} \mathrm{KCl}(10 \mathrm{~mL}$ per rinse). Capsules were gently shaken on a shaker table during each rinse, after which $\mathrm{KCl}$ extracts were decanted to create a total extract volume of $30 \mathrm{~mL}$. Extracts were then analyzed for $\mathrm{NH}_{4}{ }^{+}$and $\mathrm{NO}_{3}{ }^{-}$on an Autoanalyzer III (Bran Luebbe, Chicago, Illinois, USA) at the University of Montana Soils Laboratory. 


\section{Escape from specialist herbivores}

We initiated herbivore exclusion experiments at two of the three primary sites in Montana and Germany in April 2004. At each site, we planted 85-100 C. officinale seedlings, spaced 1-2 $\mathrm{m}$ apart in long transects across the study sites (germinated in greenhouses from seed collected at each site in 2003); transplants were necessary due to low abundance of plants in the native range in 2004. All transplants were of similar size (two to three true leaves), and the insecticide treatment was applied to alternating plants in the transects. To ensure a large enough sample size, we added a new cohort of 40-50 haphazardly selected naturally occurring rosettes in spring 2005 at the same two sites in the native range and at all three sites in the introduced range. Rosettes with at least four leaves were selected and were randomly assigned to the insecticide treatment. Half of the plants were treated with insecticide as a soil drench every three weeks during the growing season (April-September) to exclude herbivorous insects. Each plant received $1.8 \mathrm{mg}$ of imidacloprid in $30 \mathrm{~mL}$ of water, at a rate of $1800 \mathrm{~g} /$ ha (in Germany, Provado 5 WG, Bayer AG, Leverkusen, Germany, as water soluble granules; in Montana, Advanced Garden Tree and Shrub Insect Control, Bayer Advanced LLC, Birmingham, Alabama, USA, as a solution). Imidacloprid is a systemic insecticide designed to exclude sucking insects. To facilitate uptake of the insecticide in dry soils, plants treated with insecticide received an additional $70 \mathrm{~mL}$ of water for a total of $100 \mathrm{~mL}$; control plants (no insecticide) also received $100 \mathrm{~mL}$ of water. In addition to the soil drench, insecticide (or water as a control) was sprayed on the leaves every three weeks at the same time the soil drench was applied beginning in 2005, when higher leaf feeding rates were observed. The insecticide did not reduce or stimulate growth or survival, compared to only water, in a preliminary experiment in the greenhouse in Montana (with U.S. formulation of the insecticide), where plants were grown in $1-\mathrm{L}$ pots and insecticide was applied every three weeks ( 20 plants/treatment) as in the field (log plant size [ $\pm \mathrm{SE}]: 6.23 \pm 0.069$. [no insecticide] and $6.37 \pm 0.063$ [insecticide]; $F_{1,38}=2.31$, $P=0.13$ ).

We followed growth and survival of the plants at bimonthly intervals during the 2004-2006 growing seasons. Plant size was assessed by counting the number of leaves and measuring the length of the longest leaf; the product of these two measurements was the best predictor of aboveground plant biomass $\left(R^{2}=0.95\right.$, $\left.F_{1,98}=1788.1, P<0.001\right)$. We also visually estimated leaf damage at each census by classifying damage on a scale of $1-5: 1=0 \%, 2=<10 \%, 3=11-25 \%, 4=26-50 \%$, $5=>50 \%$. We measured fecundity on all plants that flowered in 2005 and 2006 by counting the number of seeds produced by each plant and dissected tap roots of flowering plants to look for evidence of weevil herbivory.

\section{Statistical analyses}

We used $t$ tests to compare plant density between ranges, as measured by the mean number of adult plants per square meter at each population in the broader surveys, and to compare the average proportion of disturbed ground between ranges, averaged across the three transects at each of our primary study sites. Differences in total plant-available nitrogen sorbed to ion-exchange resin capsules $\left(\mathrm{NO}_{3}{ }^{-}+\mathrm{NH}_{4}{ }^{+}\right)$were assessed using an ANOVA (Proc GLM, Type III sums of squares; SAS Institute 2003) with range, site(range), disturbance treatment, and range $\times$ disturbance as model factors. Tukey post hoc tests were used to compare differences between groups.

In the disturbance experiment, total first-year recruitment, cumulative recruitment over two years, seedling survival to one-year-old adults, and final plant establishment in disturbed and undisturbed plots were analyzed using ANOVA. Range, disturbance treatment, year (of experiment initiation), range $\times$ disturbance, year $X$ disturbance, and site nested within range were fixed factors in all models. Site, nested within continent, was treated as a fixed effect, because the experimental sites were not randomly chosen within each range. We acknowledge that this constrains our ability to generalize results from these specific sites to the range as a whole.We compared the categorical index of leaf herbivory between control and insecticide treatments using a Kruskal Wallis test. Effects of the insecticide treatment on plant size and fecundity were analyzed separately for each range due to unequal sample sizes and variances with an ANOVA, with site, insecticide treatment, and year as factors. Total nitrogen, numbers of seedlings, plant size, and fecundity were log-transformed, and seedling survival was arcsine square-root transformed to meet assumptions of equal variance.

\section{Demographic monitoring}

At each of the three primary sites in each range, we followed the demographic fate of all individuals in two 1 $\times 10 \mathrm{~m}$ transects that included at least 100 plants. These transects were lengthened in the native range where densities were lower to include enough individuals. New seedlings were marked in the spring (April in Germany, May in Montana) and uniquely marked the following summer, when they were one-year olds. In summer, the size of all plants was recorded by counting the number of leaves and measuring the length of the longest leaf. At this time (early July in Germany, late July in Montana), plants had set seed, and the number of seeds produced was estimated by counting the number of inflorescence branches. We counted seeds on a subset of flowering plants to estimate the relationship between inflorescences and seed production (number of seeds $=\exp (1.882+$ $1.229(\log ($ number of inflorescences $)) ; R^{2}=0.78, F_{1,297}=$ 1028.0, $P<0.001)$. To more closely examine the transition from seed to seedling, as well as the longevity 
of seeds in the seed bank, we used results from the disturbance experiment.

\section{Population model}

We used integral projection models (IPMs) to calculate the population growth rate $(\lambda)$ under different scenarios of disturbance and herbivory. IPMs are similar to size-based demographic matrix models, but they use continuous relationships between size and vital rates, rather than dividing up the population into discrete size classes (Easterling et al. 2000, Ellner and Rees 2006). Here we extend the approach of Rees et al. (2006) to incorporate four discrete stages into the integral projection model framework: three discrete early-life stages, for seeds both on adults and in the soil, and seedlings, as well as one stage for iteroparous plants (Appendix D: Fig. D1). A separate class for seedlings was necessary, because seedling size was not a good predictor of survival or growth (J. L. Williams, unpublished data). In the introduced range, where iteroparous plants can be common, a separate class was also needed for plants flowering more than once. The model structure and methods for parameter estimation are presented in detail in Appendix D and in Williams (2009).

\section{Model simulations and analyses}

An IPM generates an approximating matrix, from which properties of a more traditional stage-based matrix can be calculated (Easterling et al. 2000, Caswell 2001, Morris and Doak 2002, Ellner and Rees 2006). We calculated deterministic $\lambda$ for each site in each year based on each of the following disturbance scenarios: (1) no disturbance, (2) mean disturbance, and (3) maximum disturbance. For the mean disturbance scenario, we used parameter values from experimentally disturbed plots in each site and each year for the probability of seedling survival $\left(p_{\mathrm{SR}}\right)$ and probabilities of establishment from current seeds and those in the soil seed bank ( $p_{\mathrm{es}}$ and $\left.p_{\mathrm{eSB}}\right)$. For the maximum disturbance scenario, we used the highest average at each site for all three yearly transitions. The maximum disturbance scenario was included to explore the greatest effect disturbance could have on $\lambda$. At each of these levels of disturbance, we calculated $\lambda$ for background levels of herbivory and for a scenario when insects were excluded. For the insect exclusion scenario, we increased fecundity in the native range by the amount observed in the experiment (the only vital rate that differed significantly between treatments). Here we report average $\lambda$ for each range across three sites and three yearly transitions, with $95 \%$ confidence limits, calculated from the $t$ distribution for $n$ $=9$.

To more thoroughly examine which vital rates contributed to the observed differences in $\lambda$, we used a Life Table Response Experiment (LTRE; Caswell 2001). This approach decomposes differences in $\lambda$ between treatments into contributions by each vital rate. We compared $\lambda$ in the average disturbance scenario when insects were excluded (treatment) to a control scenario, where there was no disturbance and natural levels of herbivory. We calculated contributions of each vital rate (i) with parameter value $\left(p_{i}\right)$ as follows (Caswell 2001):

$$
\left.\Delta \lambda \approx \sum_{\text {all } p_{i}} \Delta p_{i}\left(\frac{\partial \lambda}{\partial p_{i}}\right)\right|_{p_{i \text { midpoint }}}
$$

where $\Delta \lambda$ is the difference between $\lambda$ 's, and $\Delta p_{i}$ is the difference in parameter values of a vital rate in the treatment (disturbance, no insects) and the control (no disturbance, insects). Thus the contribution of each vital rate is the difference between the vital rate in the treatment and control scenarios multiplied by the sensitivity of the vital rate. Only four vital rates were affected in these scenarios: $p_{\mathrm{SR}}, p_{\mathrm{eS}}, p_{\mathrm{eSB}}$, and fecundity $\left(f_{\mathrm{n}}(x)\right)$. Sensitivities for each vital rate were calculated from a midpoint matrix, halfway between the control and the treatment (Caswell 2001). We calculated sensitivities by using manual perturbations of 0.01 and 0.05 on each vital rate independently and examining the absolute effect on $\lambda$. Since both perturbations gave the same results, we used those from perturbations of 0.01 . All matrix simulations and analyses were done using Matlab (MathWorks 2004).

\section{Results}

\section{Plant abundance}

Cynoglossum officinale occurred, on average, at 3.5 times the density in introduced populations compared to native populations at locations sampled across ranges (native, $2.71 \pm 0.34$ adult plants $/ \mathrm{m}^{2}$, mean $\pm \mathrm{SE}$; introduced, $10.89 \pm 1.74$ adult plants $/ \mathrm{m}^{2} ; t_{21}=-5.63, P$ $<0.001)$.

\section{Effects of small-scale disturbances on early life stages}

The area covered by natural small-scale disturbances did not differ between study sites in the native and introduced ranges $\left(t_{4}=0.44, P=0.68\right)$. On average, $\sim 12 \%$ of the area at each site was disturbed (native, $12.3 \% \pm 3.7 \%$ disturbed ground, mean $\pm \mathrm{SE}$; introduced, $11.0 \% \pm 3.0 \%$ ).

Disturbance enhanced recruitment at field sites in both the native and introduced ranges; twice as many seedlings recruited into experimentally disturbed plots in the year following disturbance compared to controls (Fig. $1 \mathrm{~A} ; F_{1,156}=5.67, P=0.018$ ). This positive effect of disturbance on seedling recruitment was stronger in the introduced range than the native range, with marginal significance (range, $F_{1,156}<0.001, P=0.99$; range $\times$ disturbance, $F_{1,156}=3.51, P=0.063$ ). The effect of disturbance was also stronger for the cohort of seeds planted in 2004, for which total recruitment was higher (year, $F_{1,156}=28.93, P<0.001$; year $\times$ disturbance, $\left.F_{1,156}=5.66, P=0.019\right)$. Seedling recruitment differed among sites within each range (site(range), $F_{4,156}=6.54$, $P<0.001)$. 

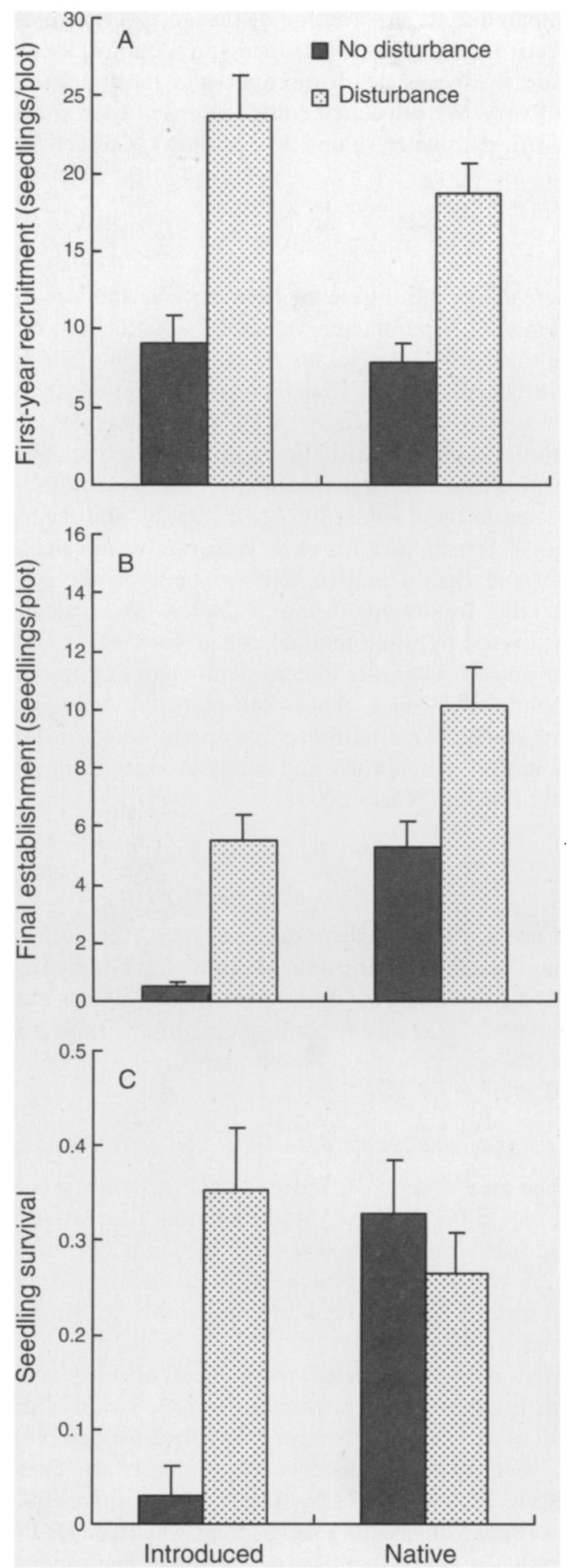

FIG. 1. Comparison of seedlings of the biennial houndstongue (Cynoglossum officinale), studied in Montana, where it is introduced, and in Germany, where it is native. (A) Number of seedlings recruited and (B) final seedling establishment in the year following disturbance and seed addition, and (C) survival of established seedlings to one-year-old plants in disturbed and undisturbed $25 \times 25 \mathrm{~cm}$ plots. Values are means $+\mathrm{SE}$.
Experimentally disturbed plots filled in with vegetation (other than $C$. officinale) more quickly in the native range than in the introduced range (Fig. 2A). By the end of the first growing season (for each cohort: July 2005 and 2006), disturbed plots in the native range had only slightly more bare space than undisturbed plots, and this difference was negligible by the following spring. Despite substantial filling in by seedlings of other species and occasional encroachment by the surrounding vegetation, disturbed plots continued to have more $C$. officinale seedlings than undisturbed plots in the July following the seed additions (Fig. $1 \mathrm{~B} ; F_{1,156}=48.7, P<$ $0.001)$. This difference was accentuated in the introduced range (range $\times$ disturbance: $F_{1,156}=3.76, P=$ 0.05 ), where there were fewer overall seedlings than in
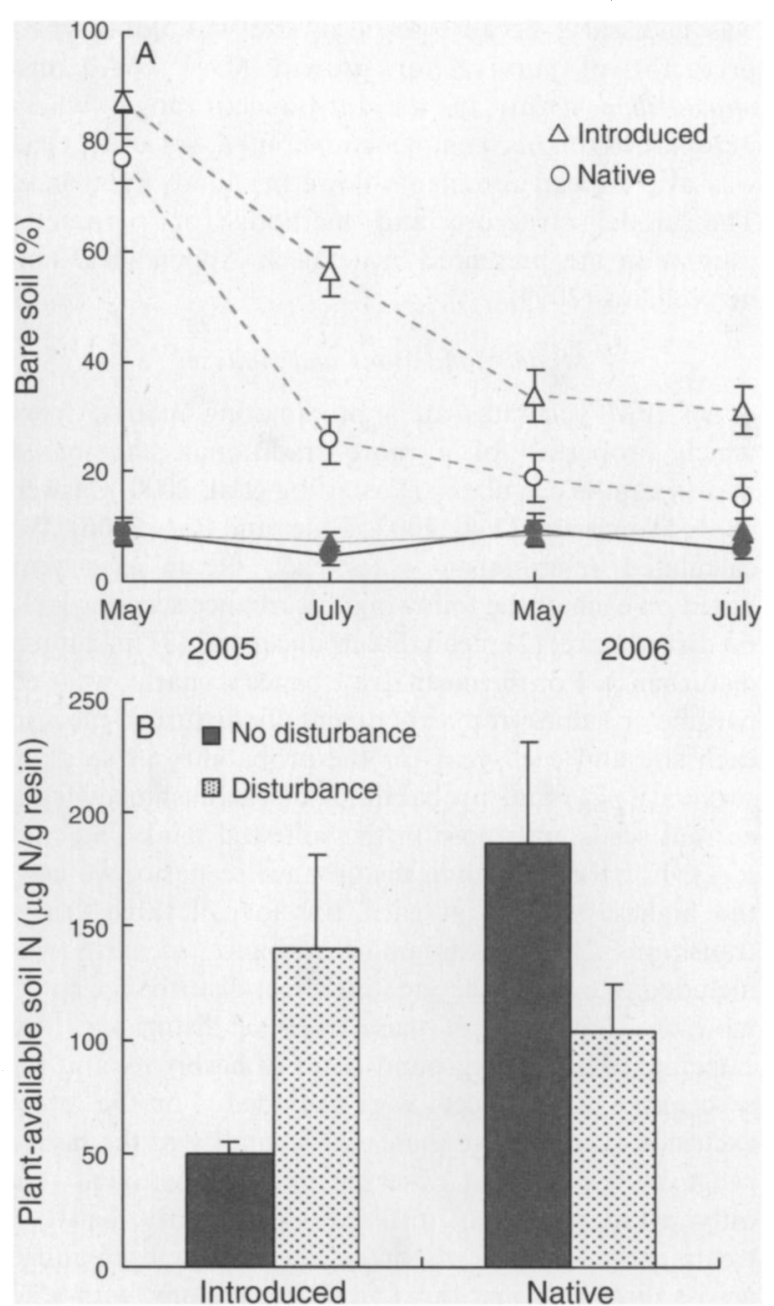

FIG. 2. (A) Percentage cover of bare ground (mean \pm SE) and (B) plant-available soil total nitrogen $\left(\mathrm{NO}_{3}{ }^{-}\right.$and $\mathrm{NH}_{4}{ }^{+}$, mean $+\mathrm{SE})$, measured per gram of total resin, in experimentally disturbed (open symbols) and undisturbed (solid symbols) $25 \times$ $25 \mathrm{~cm}$ plots in the introduced and native ranges of $C$. officinale. Plots were artificially disturbed at the end of the 2004 growing season, when bare space in disturbed plots was $100 \% . N=3$ sites in each range. 
the native range (range: $F_{1,156}=49.0, P<0.001$ ). Disturbance had a much larger positive effect on the survival of seedlings to one-year-old adults in the introduced range, where very few seedlings survived in undisturbed plots, compared to the native range, where there was little difference in survival (Fig. 1C; range $X$ disturbance: $\left.F_{1,102}=10.86, P=0.001\right)$. Survival did not depend on year $\left(F_{1,102}=1.16, P=0.28\right)$ or density of seedlings in the previous year $\left(F_{1,102}=0.50, P=0.48\right)$.

Some seedlings emerged in plots the second year following disturbance (May 2006 and 2007), when the effects of the disturbance were no longer as apparent (particularly in the native range; Fig. 2A). Total cumulative germination across two years was higher in disturbed than in undisturbed plots (cumulative number of seedlings in the introduced range [mean $\pm \mathrm{SE}$ ], $33.4 \pm$ 2.8 seedlings in disturbed vs. $17.9 \pm 2.2$ seedlings in undisturbed; and native range, $21.9 \pm 1.9$ seedlings disturbed vs. $14.3 \pm 1.6$ seedlings undisturbed). In both ranges, we very rarely observed seedling emergence in either the third year following the initial disturbance or in plots where no seeds were added, indicating that $C$. officinale does not have a persistent seed bank.

Finally, the effects of the disturbance treatment on plant-available soil nitrogen varied by range in the growing season following the creation of the disturbances (Fig. 2B; range $\times$ disturbance $F_{1,61}=11.63, P=$ 0.001 ). In the introduced range, the amount of available $\mathrm{N}$ was significantly greater in disturbed plots compared to undisturbed plots (Tukey post hoc test $P=0.034$ ), but there was no difference between treatments in the native range $(P=0.18)$. Across ranges, the amount of available $\mathrm{N}$ was similar in disturbed plots $(P=0.98)$, but undisturbed plots had higher available $\mathrm{N}$ in the native range than in the introduced range $(P<0.001)$. Although the German study site in the Robinia forest had higher total $\mathrm{N}$ than the other sites in the native range, the patterns described here were consistent across sites.

\section{Effects of insect herbivory on plant performance}

Plants in the native range suffered leaf damage by specialist flea beetles (Longitarsus spp.). In both ranges, plants were attacked by generalists such as grasshoppers and lepidopteran larvae, and by snails in the native range (J. L. Williams, personal observation). Leaf damage by specialist and generalist consumers was not significantly different between ranges (Fig. 3A; MannWhitney $\left.U=5101, \chi_{1}^{2}=1.45, P=0.23\right)$, but was significantly reduced in the insecticide treatment (Fig. $3 \mathrm{~A}$; native range, Mann-Whitney $U=4167, \chi_{1}^{2}=17.41$, $P<0.001$; introduced range, Mann-Whitney $U=$ $\left.105110, \chi_{1}^{2}=21.21, P<0.001\right)$. In the native range, $83 \%$ of plants in the control treatment had specialist root-boring weevil larvae (Mogulones cruciger) in their tap roots compared to only $11 \%$ of plants in the treatment. The weevils are not present in the United States.
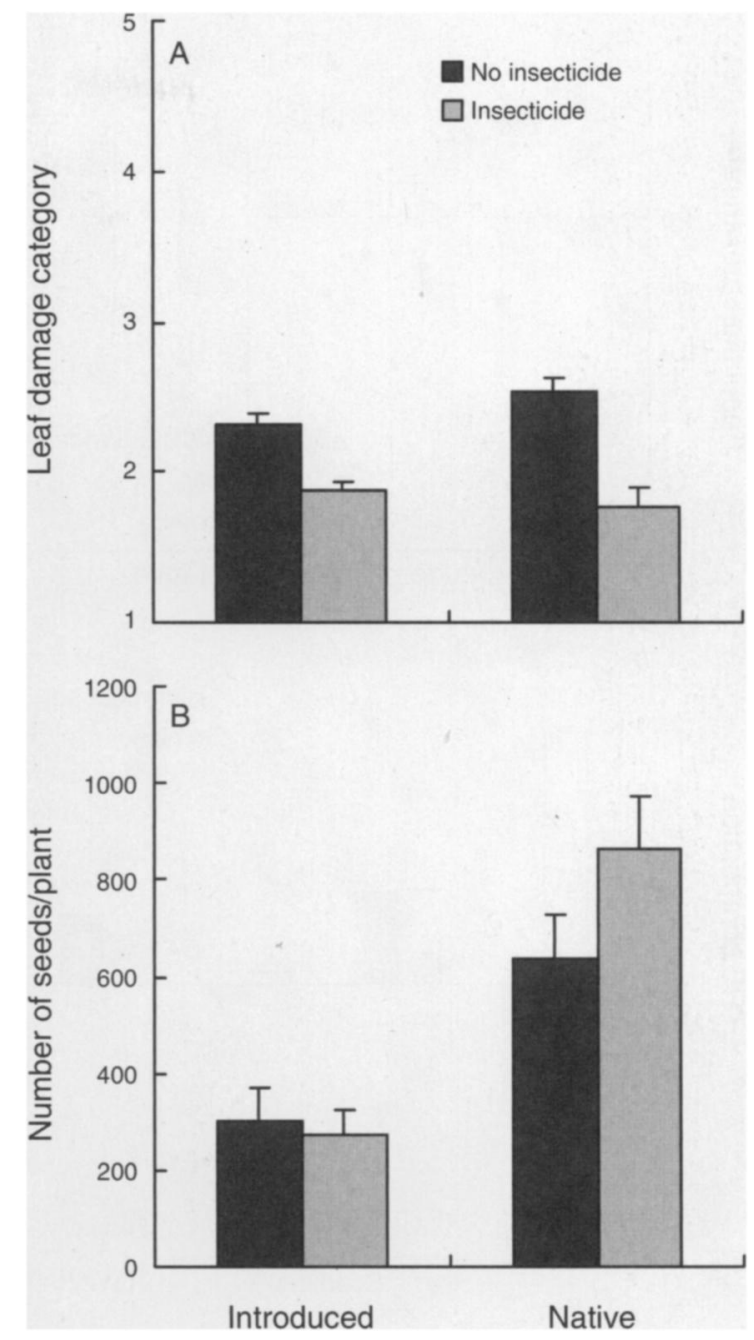

FIG. 3. Comparison of introduced vs. native $C$. officinale. (A) Effect of herbivores on leaf damage in the experiment $($ mean $+\mathrm{SE})$. Leaf damage was visually assessed on a categorical scale as follows: $1,0 \% ; 2,<10 \% ; 3,11-25 \% ; 4$, $26-50 \% ; 5,>50 \%$. (B) Fecundity (mean $+\mathrm{SE}$ ) of plants.

Insect herbivory significantly reduced plant size at field sites in the native range but not in the introduced range (native range, $F_{1,88}=9.50, P=0.003$; introduced range, $F_{1,169}=0.81, P=0.37$ ). Insect exclusion resulted in a $35 \%$ increase in seed production in the native range but had no effects on fecundity in the introduced range (Fig. 3B; native range, $F_{1,117}=4.54, P=0.015$; introduced range, $F_{1,29}=0.10, P=0.75$ ). Although experimental plants in the native range produced more seeds than those in the introduced range, this reflects the higher threshold flowering size in the introduced range (Williams 2009), leading to fewer and smaller experimental plants that flowered. In the demography plots at these sites, average fecundity did not differ between ranges (J. L. Williams, unpublished data). Insect exclusion had no effect on plant survival in either range, although many plants in both treatments died (average 

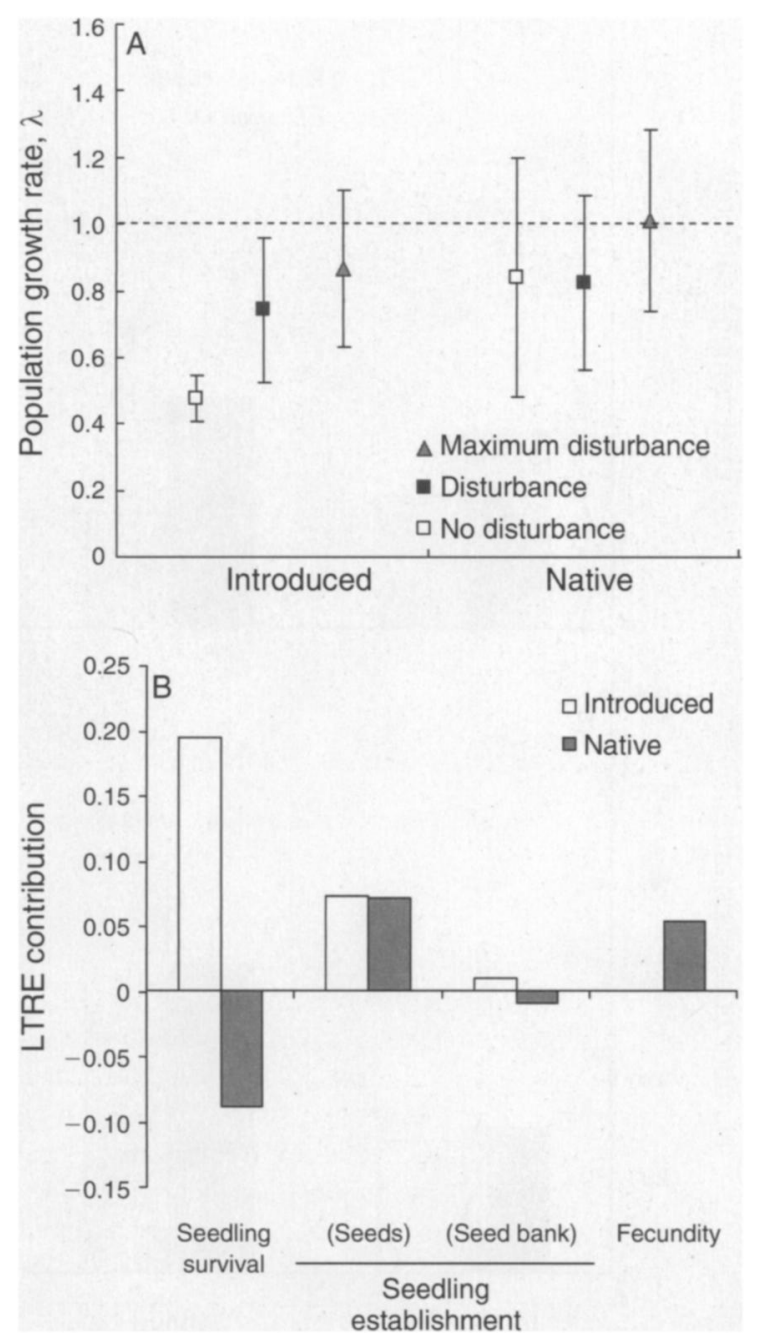

FIG. 4. Comparison of introduced vs. native $C$. officinale. (A) Effects of disturbance on estimated deterministic population growth rate $(\lambda)$ of $C$. officinale under ambient herbivory conditions. Error bars indicate $95 \%$ confidence limits that represent variation across sites and years. (B) Life Table Response Experiment (LTRE) contribution of each vital rate to $\Delta \lambda$ ([disturbance with insect exclusion] - [no disturbance with ambient herbivory]).

mortality of naturally occurring rosettes used in the experiment in the native range, insecticide 0.47 vs. no insecticide $0.31, \chi^{2}=2.29, P=0.13$; and in the introduced range, insecticide 0.38 vs. no insecticide $0.45, \chi^{2}=0.46, P=0.50$ ).

\section{Model results: translating effects of insects and disturbance on performance to effects on $\lambda$}

Small-scale disturbances had large positive effects on the population growth rate $(\lambda)$ of $C$. officinale for parameter values from study sites in the introduced range, whereas it slightly reduced forecasted $\lambda$ in the native range (Fig. 4A). When the maximum average parameter values for disturbed plots were used in simulations, $\lambda$ was higher than in the control scenario in both ranges. This was the only case in which confidence limits for $\lambda$ overlapped 1 in the introduced range (Fig. 4A). Increasing fecundity, which simulated release from insects in the native range, increased $\lambda$ in all disturbance scenarios $(\Delta \lambda$ [mean $\pm \mathrm{SE}]: 0.054 \pm 0.005)$. If specialist herbivores from the native range were brought to the introduced range and reduced fecundity by the same amount (30\%), as in the native range, they would slightly decrease $\lambda(\Delta \lambda[$ mean \pm SE]: $0.034 \pm$ 0.003).

The Life Table Response Experiment (LTRE) results showed that increased seedling survival in disturbed plots was the most important factor contributing to increased $\lambda$ in the introduced range (Fig. 4B). These results also pointed to the importance of establishment from the previous year's seeds in the introduced range. In the native range, the LTRE results indicated that seedling establishment contributed to increased $\lambda$ in the disturbance scenario, but the negative contribution from lower seedling survival in disturbed plots cancelled out the disturbance advantage (Fig. 4B). Finally, the LTRE results indicated that the effects of the release from insects on fecundity in the native range had approximately the same effect on $\lambda$ as disturbance had on recruitment.

\section{Discussion}

Surveys across portions of both ranges indicated that Cynoglossum officinale occurs at higher density in its introduced range compared to in its native range, at least in the two regions of these surveys. Although this pattern is often assumed in studies of invasive plants, it is rarely documented, and still must be interpreted with caution for $C$. officinale because we were unable to randomly select sites for these surveys. We tested two hypotheses that may explain this difference in abundance across continents. We found that both small-scale disturbances and insect herbivores differentially affected plant performance at the primary field sites in each range. Herbivores reduced plant size and fecundity in the native range but had little effect on plant performance in the introduced range. Small-scale experimental disturbances enhanced seedling recruitment in both ranges, but subsequent seedling survival was more positively affected by disturbance in the introduced range. When these differences in performance between ranges were incorporated into population models that integrated all life stages, the model results suggest that, at least in the populations we studied, the response to small-scale disturbances in the introduced range was much larger than the predicted effects of release from specialist herbivorous insects. We discuss the mechanisms that might lead to these differences between ranges and the strengths and challenges of using a biogeographical approach combined with population modeling to examine exotic plant success. 


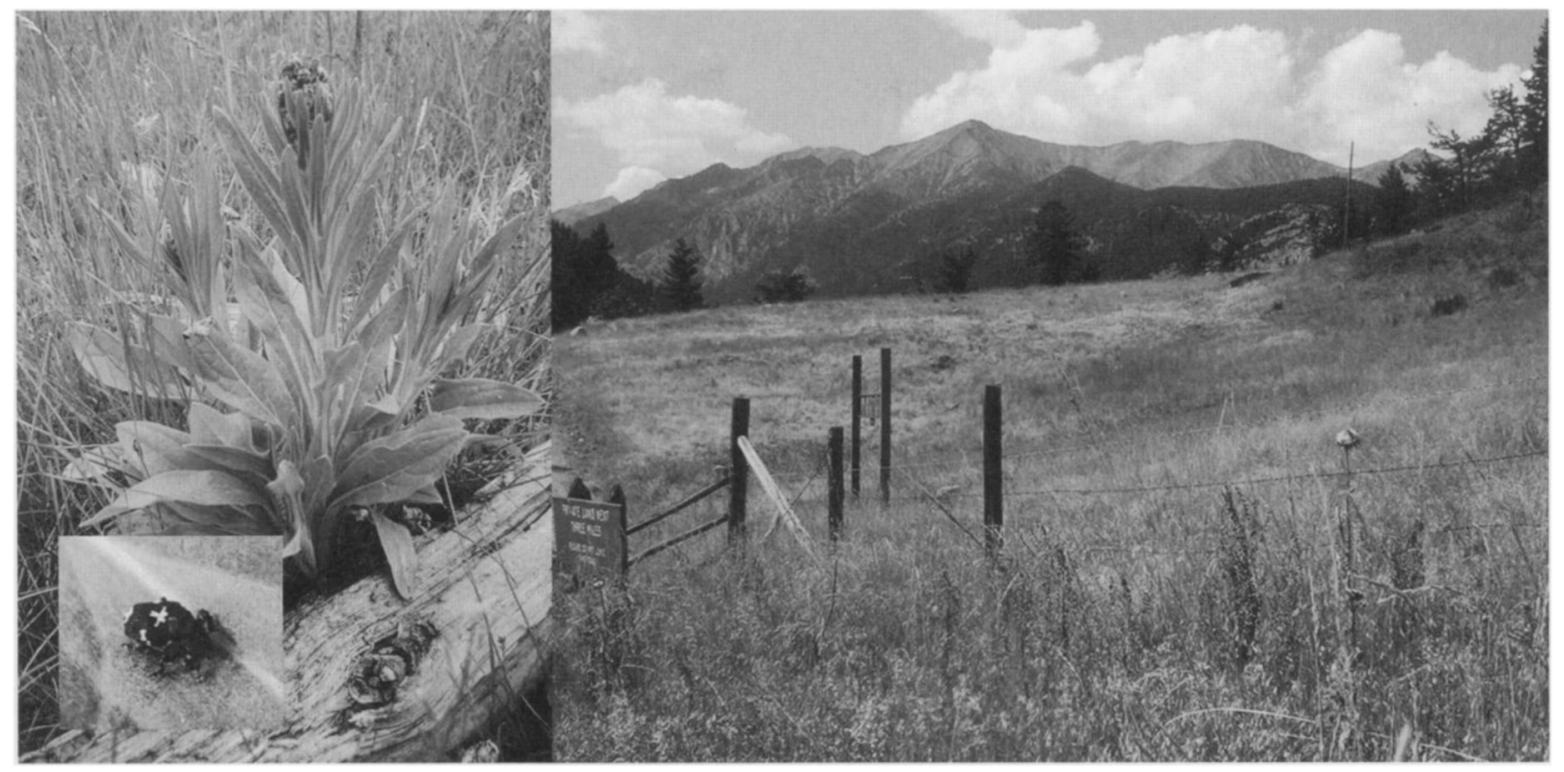

Plate 1. (Left) Cynoglossum officinale beginning to bolt in late spring in the introduced range; (left, inset) Mogulones cruciger, the primary specialist herbivore in the native range; and (right) C. officinale growing in the Crazy Mountains (Montana, USA), one of the additional sites where density was quantified. Photo credits: J. L. Williams.

\section{Disturbance}

Recruitment in both ranges was enhanced by experimental disturbances, as was previously shown at the edge of the native range, in the Netherlands (de Jong and Klinkhamer 1988). This result is not unexpected (Sletvold and Rydgren 2007), as disturbance has long been appreciated as a factor that can facilitate invasion by ruderal plants (Hobbs and Huenneke 1992, Williamson 1996, Mack et al. 2000, Lockwood et al. 2007). Given that disturbance enhances recruitment of $C$. officinale, if suitable habitats in North America were more disturbed than those in Europe, this might explain the greater abundance of this plant in North America vs. Europe. Yet, we did not find differences in the amount of disturbed ground between study sites in each range. Moreover, in broader-scale surveys, levels of disturbance seemed at least superficially similar in grassland habitat on both continents. However, we found the surprising result that nearly identical levels of disturbance had differentially greater effects on recruitment, seedling survival, and ultimately, population growth rate of $C$. officinale in the introduced vs. the native range (Figs. 1 and 4A). In the native range, estimates of population growth were elevated only under a maximum disturbance scenario, when the positive influence on recruitment outweighed the slight negative effect on seedling survival (Fig. 4B). In contrast, in the introduced range, the increases in $\lambda$ in both the disturbance and maximum disturbance scenarios were driven by much higher seedling survival and establishment in disturbed plots (Fig. 4B). Only one other study has examined whether an exotic plant responds differently to small- scale disturbances across ranges. Hierro et al. (2006) found that the annual exotic invader Centaurea stolstitialis had greater recruitment in similarly disturbed habitat in its introduced vs. native range. Whether such differential responses to disturbance are a more general phenomenon among plant invaders is unknown.

In addition to disturbance increasing recruitment more in the introduced than native range, $\lambda$ in the introduced range was substantially reduced in scenarios with no small disturbances. In the native range, disturbed patches quickly filled in with seedlings and occasional encroachment of other plant species (Fig. 2A; J. L. Williams, personal observation), but in the introduced range, colonization by local plants was slower, providing temporary competition-free space for C. officinale. Thus it may be the slow colonization of disturbed patches in the introduced range by native plants, whether by seed or vegetative reproduction, that allows $C$. officinale to attain higher abundance there. The speed at which disturbed plots fill in is necessarily dependent on the life histories of the particular species at each site, and thus our results will be most applicable to other grassland populations.

The opposite response of plant-available soil nitrogen to artificial disturbances across ranges may also contribute to the differences in the effect of small-scale disturbances on recruitment and survival. In the native range, soil nitrogen was lower in disturbed plots in the growing season following the disturbance, while the reverse occurred in the introduced range (Fig. 2B). These differences might have been due to differences between ranges in the timing of rainfall (Appendix B), and how this affects $\mathrm{N}$ immobilization by microbes or $\mathrm{N}$ 
leaching. If nitrogen is limiting to plant growth, then disturbed plots would be more favorable than undisturbed in the introduced range, but not in the native range.

\section{Escape from specialist insect herbivores}

The enemy escape hypothesis has been the most broadly cited explanation for success of invasive species (Keane and Crawley 2002), but complete tests of it that examine impacts of enemies in both ranges and their consequences for population growth have not been performed. In the native range of $C$. officinale, we found that insects negatively impacted plant performance by reducing both size and fecundity during the relatively short-term duration (three years) of our study (Fig. 3B). The observed $35 \%$ increase in fecundity when insects were excluded was remarkably similar to results from a previous study on $C$. officinale in sand dune habitats in the Netherlands (Prins et al. 1992). This damage was caused mainly by specialists, which are absent in the United States. The attack rate of plants by the specialist root-boring Mogulones cruciger at the two experimental study sites was also similar to that observed across 11 additional sites in the native range (J. L. Williams, unpublished data). These reductions in plant performance appear to limit population growth rate, albeit slightly. The results are consistent with expectations of the effects of native insects on native plants. In a review of studies that examined effects of native herbivores on native plants, mainly perennial forbs, Maron and Crone (2006) reported an average reduction in $\lambda$ of $0.11 \pm 0.14$ (mean \pm SE) due to herbivores that were not seed predators. The small decrease in $\lambda$ that we observed under ambient herbivore conditions in the native range is less than the average reduction, but well within the reported range.

In the introduced range, where herbivores did not affect plant performance (Fig. 3B), has $C$. officinale benefited from escape from its enemies? The release from specialist insects may have contributed to increased population success, but it is unlikely to drive the entire pattern if the main effect of specialist insects is to reduce fecundity. While we cannot exclude the possibility of insects affecting other vital rates in the native range, we detected no other impacts in our experiment. This illustrates an important point: estimates of the impacts of herbivores on plant performance between regions do not in themselves fully test the enemy escape hypothesis. This is because enhanced performance of a particular vital rate such as fecundity, as a result of enemy escape, does not necessarily lead to large effects on population growth.

\section{Strengths and challenges of a biogeographical approach combined with population modeling}

Our approach of combining field experiments with population modeling permits us to test the relative importance of alternative causal factors in affecting the population growth of a plant at home and abroad. Although both disturbance and insect herbivores affected plant performance in our experiments, this approach allows us to suggest that the increased response to disturbance in the introduced range matters more than escape from specialist insects in explaining the success of $C$. officinale, at least in the regions where the experiments were performed. We could not have reached this level of insight by performing experiments only in one range. Nor could we have compared the relative importance of these two factors using only the experimental results, because disturbance and herbivory affect different life stages, and effects on one life stage may or may not translate to meaningful impacts on population growth.

To translate the relative effects of disturbance and herbivory on individual performance to population level effects, we combined experimental results with demographic data in population models. This is a powerful approach in that it enables one to translate impacts on individuals at a particular life stage to the growth or decline of an entire population and to compare the relative importance of more than one factor. However, one drawback of this approach is that the rate at which a population is growing or declining does not always reflect the absolute number of individuals at the current time. In this study, even though estimated $\lambda$ s were on average less than one, indicating declining populations in both ranges, overall plant density was higher in the introduced range. This somewhat nonintuitive result stems from population models estimating exponential growth rates $(\lambda)$ at equilibrium. Thus for populations not yet at equilibrium, the absolute values of $\lambda$ between ranges are less meaningful than comparing the relative values within a range. This is because the magnitude and direction of the differences between the control and treatment scenarios were similar within a population, regardless of the absolute value of $\lambda$.

Our work also illustrates several challenges of conducting research in both ranges. One challenge involves choosing experimental populations. For logistical reasons we could only examine three populations on each continent. This necessarily reduced the statistical power to detect differences in vital rates across continents and is obviously a small sample from which to generalize across an entire range. Since we deliberately chose populations in both Europe and North America where conditions (plant density, climate, and so forth) were as similar as possible, we treated these sites as a fixed factor in our analyses. This means one must be cautious in extrapolating the results, since the scope of inference of this study is limited to the habitats, climate, and grazing regimes where we have studied this species. While it would be desirable to have applied our methodology within many more populations across each range so as to have a more representative sample of conditions, this is logistically very difficult. Overcoming this obstacle represents a major future challenge for the 
field of invasion biology at large. A second challenge is that there can be considerable spatial variation in demography within a range, and in our case, substantial year-to-year variation in vital rates. This temporal and spatial variability potentially obscures continental differences in demography that might become clear with a longer study at more sites. Despite these challenges in selecting populations that are representative of a range, we argue that even with a limited number of sites, much greater insight can be gained than when studies are conducted only in the introduced range.

\section{Conclusion}

Our study tested the relative importance of two factors that may be responsible for exotic plant success. In so doing, it lends insight into effective management strategies for $C$. officinale populations in the introduced range. If specialist biocontrol agents such as $M$. cruciger were to be effective, our results suggest they would need to have much larger effects on both performance and population growth in the introduced range than was observed in the native range. It is difficult to predict what effect these specialist insects would have if they were introduced as biocontrol agents. Preliminary evidence from a biocontrol program in Canada suggests that $M$. cruciger has the potential to increase the rate of population decline (De Clerck-Floate and Wikeem 2009) when other factors that limit populations, such as drought or intrinsic cycling, are also operating. Future studies on exotic plants that examine mechanisms for success in both ranges have great potential for elucidating the causes of increased success and may be especially useful for improving eradication programs in the introduced range.

\section{ACKNOWLEDGMENTS}

We thank Carrie Craig, Antje Thondorf, and numerous other field assistants in both Montana and Germany for help in maintaining experiments and collecting demographic data. This project would not have been possible without their hard work. We are grateful to Elizabeth Crone, who provided valuable advice on constructing the population models. We also thank R. Callaway, E. Crone, D. Emlen, and A. Sala for helpful comments on previous versions of this manuscript. Support for this study to J. L. Williams was provided by an NSF Graduate Research Fellowship, an NSF Doctoral Dissertation Improvement Grant (DEB 05-08102), a Sigma Xi Grant-in-Aid of Research, and a University of Montana Graduate Council Award; and by the National Center for Ecological Analysis and Synthesis, a Center funded by NSF (Grant \#EF-0553768), the University of California-Santa Barbara, and the State of California. J. L. Maron was supported by NSF grants DEB0318719 and DEB-0614406.

\section{Literature Cited}

Baker, H. G. 1974. The evolution of weeds. Annual Review of Ecology and Systematics 5:1-24.

Boorman, L. A., and R. M. Fuller. 1984. The comparative ecology of two sand dune biennials: Lactuca virosa L. and Cynoglossum officinale L. New Phytologist 69:609-629.

Britton-Simmons, K. H., and K. C. Abbott. 2008. Short- and long-term effects of disturbance and propagule pressure on a biological invasion. Journal of Ecology 96:68-77.
Burns, J. H. 2008. Demographic performance predicts invasiveness of species in the Commelinaceae under high-nutrient conditions. Ecological Applications 18:335-346.

Caswell, H. 2001. Matrix population models: construction, analysis, and interpretation. Second edition. Sinauer, Sunderland, Massachusetts, USA.

Davis, M. A., J. P. Grime, and K. Thompson. 2000. Fluctuating resources in plant communities: a general theory of invasibility. Journal of Ecology 88:528-534.

De Clerck-Floate, R., and B. Wikeem. 2009. Influence of release size on establishment and impact of a root weevil for the biocontrol of houndstongue (Cynoglossum officinale). Biocontrol Science and Technology 19:169-183.

De Jong, T. J., and P. G. L. Klinkhamer. 1988. Population ecology of the biennials Cirsium vulgare and Cynoglossum officinale in a coastal sand-dune area. Journal of Ecology 76: 366-382.

De Jong, T. J., P. G. L. Klinkhamer, and L. A. Boorman. 1990. Biological flora of the British Isles: Cynoglossum officinale $\mathrm{L}$. Journal of Ecology 78:1123-1144.

DeWalt, S. J., J. S. Denslow, and K. Ickes. 2004. Naturalenemy release facilitates habitat expansion of the invasive tropical shrub Clidemia hirta. Ecology 85:471-483.

Easterling, M. R., S. P. Ellner, and P. M. Dixon. 2000. Sizespecific sensitivity: applying a new structured population model. Ecology 81:694-708.

Ellner, S. P., and M. Rees. 2006. Integral projection models for species with complex demography. American Naturalist 167: 410-428.

Elton, C. S. 1958. The ecology of invasions by plants and animals. Methuen, London, UK.

Franco, M., and J. Silvertown. 2004. A comparative demography of plants based upon elasticities of vital rates. Ecology 85:531-538.

Harper, J. L. 1977. Population biology of plants. Academic Press, London, UK.

Hierro, J. L., J. L. Maron, and R. M. Callaway. 2005. A biogeographical approach to plant invasions: the importance of studying exotics in their introduced and native range. Journal of Ecology 93:5-15.

Hierro, J. L., D. Villarreal, Ö. Eren, J. M. Graham, and R. M. Callaway. 2006. Disturbance facilitates invasion: the effects are stronger abroad than at home. American Naturalist 168: $144-156$.

Hobbs, R. J. 1989. The nature and effects of disturbance relative to invasions. Pages $389-405$ in J. A. Drake, H. A. Mooney, F. di Castri, R. H. Groves, F. J. Kruger, M. Rejmanek, and M. H. Williamson, editors. Biological invasions: a global perspective. Wiley and Sons, New York, New York, USA.

Hobbs, R. J., and L. F. Huenneke. 1992. Disturbance, diversity, and invasion: implications for conservation. Conservation Biology 6:324-337.

Jongejans, E., A. W. Sheppard, and K. Shea. 2006. What controls the population dynamics of the invasive thistle Carduus nutans in its native range? Journal of Applied Ecology 43:877-886.

Keane, R. M., and M. J. Crawley. 2002. Exotic plant invasions and the enemy release hypothesis. Trends in Ecology and Evolution 17:164-170.

Kellogg, C. H., and S. D. Bridgham. 2004. Disturbance, herbivory, and propagule dispersal control dominance of an invasive grass. Biological Invasions 6:319-329.

Lockwood, J. L., M. F. Hoopes, and M. P. Marchetti. 2007. Invasion ecology. Blackwell Publishing, Malden, Massachusetts, USA.

Mack, R. N., D. Simberloff, W. M. Lonsdale, H. Evans, M. Clout, and F. A. Bazzaz. 2000. Biotic invasions: causes, epidemiology, global consequences, and control. Ecological Applications 10:689-710. 
Maron, J. L., and E. E. Crone. 2006. Herbivory: effects on plant abundance, distribution and population growth. Proceedings of the Royal Society B 273:2575-2584.

Maron, J. L., and M. Vilà. 2001. When do herbivores affect plant invasion? Evidence for the natural enemies and biotic resistance hypotheses. Oikos 95:361-373.

MathWorks. 2004. Matlab. Release 14. MathWorks, Natick, Massachusetts, USA

Memmott, J., S. V. Fowler, Q. Paynter, A. W. Sheppard, and P. Syrett. 2000. The invertebrate fauna on broom, Cytisus scoparius, in two native and two exotic habitats. Acta Oecologia 21:213-222.

Mitchell, C. E., and A. G. Power. 2003. Release of invasive plants from fungal and viral pathogens. Nature 421:625627.

Morris, W. F., and D. F. Doak. 2002. Quantitative conservation biology. Sinauer, Sunderland, Massachusetts, USA.

Parker, I. M. 2001. Safe site and seed limitation in Cytisus scoparius (Scotch broom): invasibility, disturbance, and the role of cryptogams in a glacial outwash prairie. Biological Invasions 3:323-332.

Prins, A. H., H. W. Nell, and P. G. L. Klinkhamer. 1992. Sizedependent root herbivory on Cynoglossum officinale. Oikos 65:409-413.

Rees, M., D. Z. Childs, C. J. E. Metcalf, K. E. Rose, A. W. Sheppard, and P. J. Grubb. 2006. Seed dormancy and delayed flowering in monocarpic plants: selective interactions in a stochastic environment. American Naturalist 168:E53E71.

Reinhart, K. O., A. Packer, W. H. Van der Putten, and K. Clay. 2003. Plant-soil biota interactions and spatial distribution of black cherry in its native and invasive ranges. Ecology Letters 6:1046-1050.

SAS Institute. 2003. Proc GLM. Version 9.1. SAS Institute, Cary, North Carolina, USA.
Schwarzlaender, M. 1997. Bionomics of Mogulones cruciger (Coleoptera: Curculionidae), a below-ground herbivore for the biological control of hound's-tongue. Environmental Entomology 26:357-365.

Schwarzlaender, M. 2000. Host specificity of Longitarsus quadriguttatus Pont., a below-ground herbivore for the biological control of houndstongue. Biological Control 18: $18-26$.

Seabloom, E. W., W. S. Harpole, O. J. Reichman, and D. Tilman. 2003. Invasion, competitive dominance, and resource use by exotic and native California grassland species. Proceedings of the National Academy of Sciences USA 100:13384-13389.

Shea, K., and P. Chesson. 2002. Community ecology theory as a framework for biological invasions. Trends in Ecology and Evolution 17:170-176.

Sletvold, N., and K. Rydgren. 2007. Population dynamics in Digitalis purpurea: the interaction of disturbance and seed bank dynamics. Journal of Ecology 95:1346-1359.

Torchin, M. E., K. D. Lafferty, A. P. Dobson, V. J. McKenzie, and A. M. Kuris. 2003. Introduced species and their missing parasites. Nature 421:628-630.

Upadhyaya, M. K., H. R. Tilsner, and M. D. Pitt. 1988. The biology of Canadian weeds. 87. Cynoglossum officinale L. Canadian Journal of Plant Science 68:763-774.

Vilà, M., J. L. Maron, and L. Marco. 2005. Evidence for the enemy release hypothesis in Hypericum perforatum. Oecologia 142:474-479.

Williams, J. L. 2009. Flowering life-history strategies differ between the native and introduced ranges of a monocarpic perennial. American Naturalist 174:660-672.

Williamson, M. H. 1996. Biological invasions. Chapman and Hall, London, UK.

Wolfe, L. M. 2002. Why alien invaders succeed: support for the escape-from-enemy hypothesis. American Naturalist 160: 705-711.

\section{APPENDIX A}

Maps depicting approximate locations of populations sampled in the native and introduced ranges of $C$. officinale (Ecological Archives E091-094-A1).

\section{APPENDIX B}

Monthly precipitation for local weather stations in each range (Ecological Archives E091-094-A2).

\section{APPENDIX C}

Site descriptions and lists of common plant species (Ecological Archives E091-094-A3).

\section{APPENDIX D}

Description of model structure and methods for parameter estimation (Ecological Archives E091-094-A4). 